\title{
Kinematic and Rock Mass Classification Assessment of Road Cut Slopes along with Karakoram Highway in Northern, Pakistan
}

\author{
Asif Razzak $^{1}$ \\ asifgsp@live.com \\ Faculty of Engineering, China University of Geoscience, Wuhan 430074, China \\ Professor Tang Humming ${ }^{1}$ \\ tanqinhm@cug.edu.cn \\ Faculty of Engineering, China University of Geosciences, Wuhan 430074, China. \\ Professor Lei Huang ${ }^{2}$ \\ Three Gorges Research Center for Geohazards, Ministry of Education, China University of \\ Geosciences, Wuhan, Hubei 430074, China \\ huanglei@cug.edu.cn \\ Ijaz Ahmed ${ }^{3}$ \\ Ijaz_qaisrani@hotmail.com \\ Geological Survey of Pakistan. \\ Correspondence: tanqhm@cug.cn ${ }^{1}$ asifgsp@live.com ${ }^{2}$
}

\begin{abstract}
Karakoram highway (K.K.H.) the only road link between two countries China and Pakistan. This road network is essential for two countries due to its strategic location and socioeconomic. The highway is more vulnerable due to landslide disasters, especially in rain and snow melting seasons, and different kinds of mass movement activities have occurred along K.K.H., such as rockfall, debris flow, and snow avalanche. The slope stability problems are widespread along with Karakorum (K.K.H.) between Besham city and the Dasu area because of the high seismic zone, rainfall, snow melting, and complex geology slope geometry, week, and adverse discontinuities sets. The detailed fieldwork was done along the Karakorum highway to minimize the risk of slope stability and for planning purposes in Besham to Dasu area and selected nine road-cut slopes. However, in these nine selected roadcut slopes, three slopes were already failed, four slopes are partially stable, and two slopes were stable. Both kinematic and empirical approaches are applied on all these nine road cut slopes and their discontinuities. The kinematic result has shown that all kinds of mode failure such as Toppling, Planar, and Wedge failure mode occurred in these slopes. The $\mathrm{RMRb}$ result has shown that all discounters lie in between fair to good rock. Both discrete and continuous (S.M.R.) results show that all discontinuity sets lie between the unstable, partially stable, and stable conditions.
\end{abstract}

Keywords: Kinematic; Rock Mass Classification; R.M.R; S.M.R; Rock Slope Stability. 


\section{Introduction.}

Rock-cut slope instability in mountain areas is a significant disaster that frequently happened and causes property damage, economic losses, repair cost, and human injuries and deaths. [1]. Human-made excavation in mountainous areas the stability of natural rock slopes, such as highway and railways situated in river valleys, maybe place under these slopes or maybe cut the toe, which may be harmful to stability. The regional tectonic setting is one of the variables that can affect the natural rock slopes. The safety factor can only be marginally more significant than unity if there is rapid uplift of landmass and subsequent water downriver and streams along with seismicity that break and displace the slope. These conditions occur in high seismic areas, such as the Himalayas, Central Asia, and Pacific Rim. [2]

Slope stability problems constitute a significant concern in this area due to high seismicity, high terrain, angle of slope, weathering, and human-made factors. Many techniques and methods to evaluate slope stability are famous in researchers and scientific communities, such as Limit equilibrium, numerical analysis, empirical approach, and kinematic analysis. Limit equilibrium is a traditional and well-established method. However, the Limit equilibrium method may not stress-strain the relationship of the soil. Still, it can assess the factor of safety without the knowledge of the initial condition[3]. The Numerical analysis method is more modern than traditional equilibrium methods. The Numerical method is frequently used in open pit mining and landslide studies, where attention is mostly based on slope change rather than on the relative magnitude of resistance and displacement. [2].

Kinematic analysis is a straightforward method for structurally controlled failure modes, such as toppling, planar, and wedge failure mode. This method determines the direction of discontinuities, the slope orientation, and the assumed possible friction angle along the discontinuity surface. [4] . Richard first described stereographic projection techniques for slope failure mode in the kinematic analysis[5]. Rock mass classification systems are an essential and widely used tool worldwide for designing a rock mass structure such as highways, tunnels, dams, underground power plants, and spillways. Rock mass classifications are universally adopted and famous systems in engineers around the world. A straightforward athematic algorithm gives engineers quantitative data and guidelines to improve the rock mass inherent and structural parameters.[1] A variety of rock mass classification has developed to provide information on rock masses; for example, there are seven rock mass classification systems only in Japan. Every one built to meet a different set of requirements [6]. Some of the rock mass classification initially developed for underground excavation is used for slopes such as Q and R.M.R. systems or updating slopes. (e.g., R.M.S., S.M.R., SRMR.)[1] 
The world's best-recognized and published rock mass classification systems for rock slopes are as follows (1) RQD., Rock Quality Designation.[7] (2) Q., Rock Tunneling Quality.[8] (3) R.M.R., rock mass rating.[9][10] (2) S.M.R., Slope mass rating[11] (3) CSMR, Chinese slope mass rating[12]. (4) GSI., Geological Strength Index.[13] [14](5)M-RMR modified rock mass rating[15] (6)SSPC, Slope probability classification[16]. (7) S.M.R. slope mass rating modified. [17]. In the above-discussed classification system, the S.M.R. classification system is unique and famous used throughout the world. However, it was obtained from basic $\mathrm{RMR}_{\mathrm{b}}$, but due to the lack of definition and an extreme range of correction factors, the R.M.R. system is complicated to use. However, both R.M.R. and S.M.R. classification are discrete functions determined by the variable values that control the parameters. [18].

The average rainfall is around $1000 \mathrm{~mm}$ annually in the study area according to the world bank climate data from 1901-2016 [19], and the minimum average temperature is $4.71^{\circ} \mathrm{C}$ in January, and the maximum average temperature is $24.14^{\circ} \mathrm{C}$ in July. Fig 1 . The intense rainfall from January to April and August to September in the study area also cause slope failure. The chosen study area is significant due to the highly active landslide zone identified in previous research [20]. However, in this field study, we identified that the study area is highly susceptible to landslide hazards along the Karakorum highway due to its rock mass characteristics. However, the other trigging factors also involved rock slope stability assessments in the study area, such as rainfall and seismicity, but our focus was on rocks mass characteristics. Therefore, we chose and focused on empirical assessment in this study.

This study aims to identify (1) Rock mass quality, (2) Potential mode of failure (3) Stability conditions of the selected rock slopes because the study area is highly susceptible to rock slope failure. Meanwhile, we used Kinematic and Empirical methods to assess highly fractured road cut slopes along the Karakorum highway.

We evaluate both discreet and continuous S.M.R. function to obtain better rock slope stability along the Karakorum highway. An open-source software SMRTool[21] was used for this analysis. 


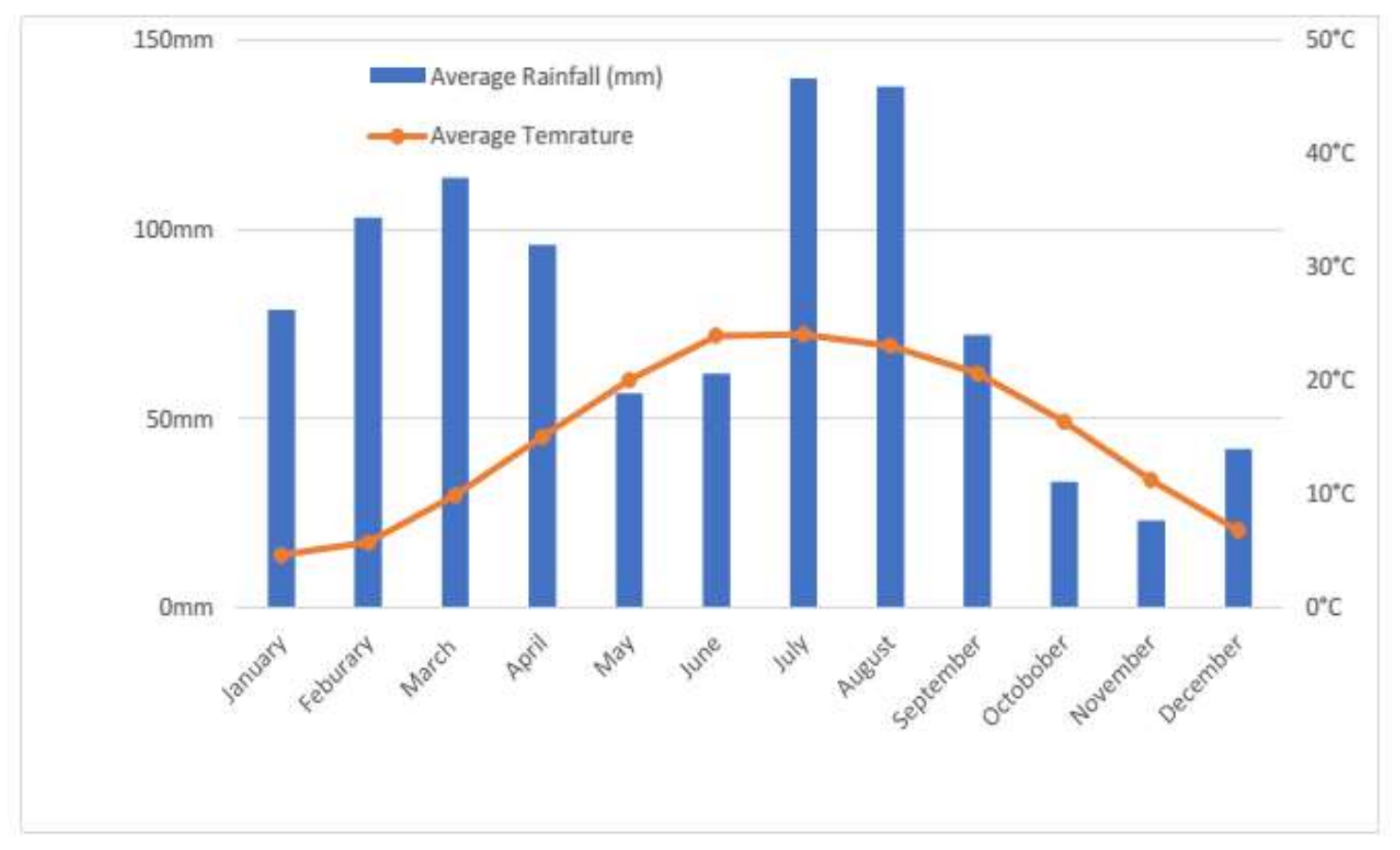

Figure.1 World bank climate data of Bisham city from 1991-2016.

\section{Geology and tectonic framework of the study area}

The study area's geology comprised the Besham group, Mansehra granite, and the Jijal complex (Fig.2). The Besham and Mansehra granite is part of the Indo Pakistan Plate. The Besham sequence is currently a tectonic gap due to the rapid uplift and deep erosion along the Indus canyon, where the Indian plate Archean to the Proterozoic crystalline basement is expose[22]. This sequence was first described by[23] as a Besham group and named this after Besham small town on the Indus canyon. He further divided it into two formations: (1) Lower one Chail formation comprised of dominantly pelitic, slate phyllites, pareamphibolite, a different type of schists gneisses, subordinate bands of calcareous and psammitic rocks. (2) The Upper one Banna formation was dominantly calcareous.

The Mansehra granite occurs west of Hazara-Kashmir syntaxis as a vast pluton and continues up to the Indus river[24]. The small patches of granitic gneiss and porphyritic granite are well exposed along the Karakorum highway in the study area. Jijal complex is part of the Kohistan-Ladakh magmatic arc. Jijal complex comprises ultramafic and mafic rocks. The rocks of garnet gabbro, garnet pyroxenite, dunnite, pyroxenite, and serpentinite in the Jijal complex are well exposed in the study area Fig.2.The Besham group show traces of individual mineral having crushed and stains quartzes, while the Jijal complex becomes massive and sheared. It is highly deformed and tectonic to the Jijal-complex with the MMT in the North and Patan fault in the south. 
The potion of K.K.H. from Bisham to Dasu also passthrough the IKNZ. The IKNZ is a highly active wedge-shaped 50-kilometer-wide structure with a shallow and mid-crustal region. The IKNZ is the most seismically active structure in the region, and this structure can generate significant events. It is mainly thrust fault parallel to the overall pattern of the MBT to the S.E. of Muzaffarabad with N.E. striking and N.E. dipping plane.[25].

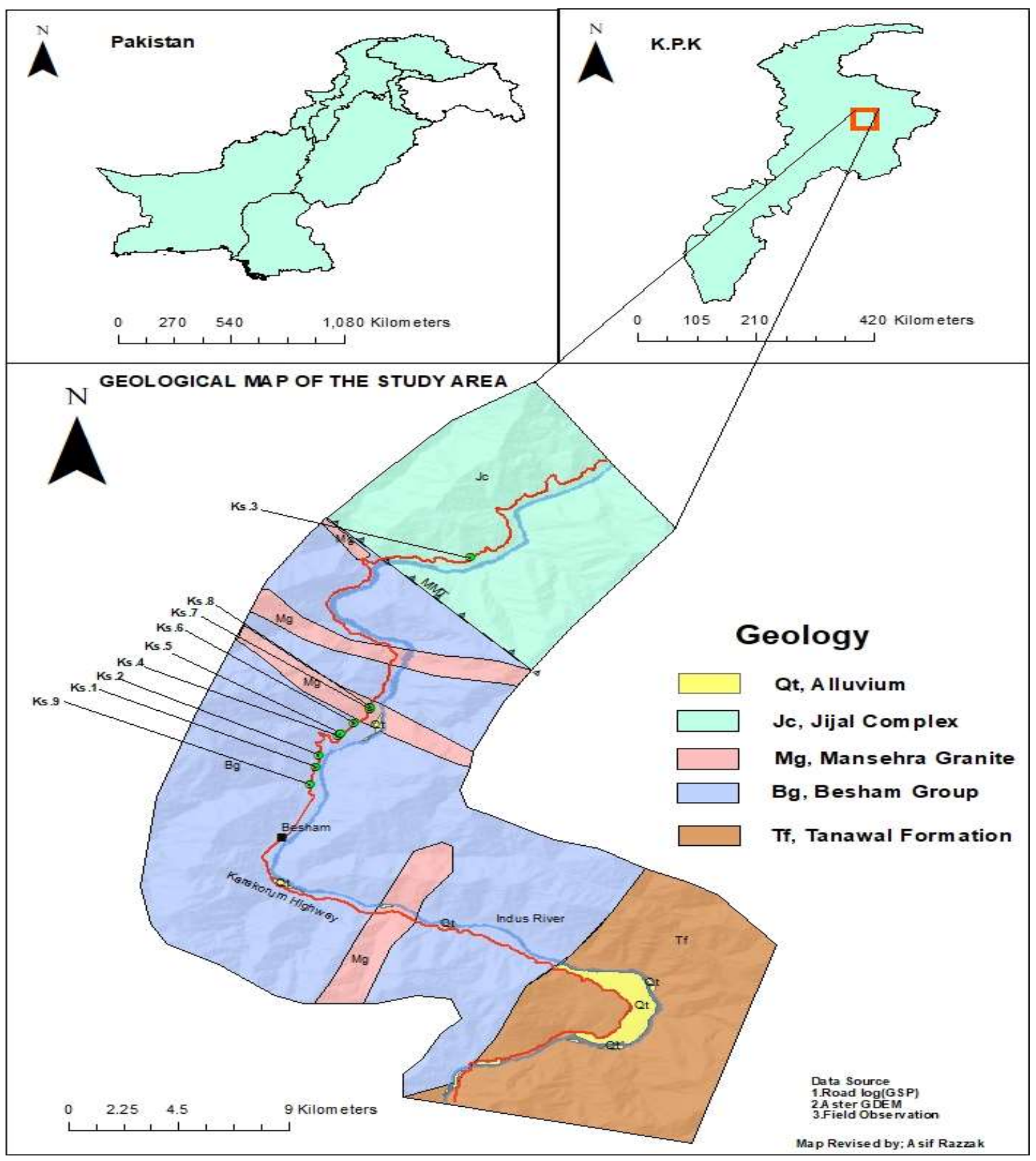

Figure 2. The map has shown the stratigraphy and slope location site of the study area, and this map revised from field and G.S.P., road $\log [26]$ (a) Tf, Tanawal formation (b) Bg, Besham group (c) Mc, Mansehra granite (d) Jc, Jijal complex (e) Qt, Alluvium 


\section{Feld Investigation and Data Evaluation.}

In both natural and engineering rock slopes, a geological structure such as fault, fold, and discontinuities play a critical role in both natural and engineering rock slope stability and behavior [27].

The effect of rock slope is also greatly affected by the rock structural geology, where the slope is excavated. Structural geology refers to rock breaks that occur naturally, such as bedding plane, joint, and fault, commonly called discontinuities. The rock slope related properties of discontinuities include orientation, roughness, and infilling, and persistence. The importance of discontinuities is that it's much more influential in the plane of weakness in the stronger intact rock, and failure appears to occur along the surface.[2]

We conduct detailed fieldwork for data collection along Karakorum highway northwest Khyber Pakhtunkhwa province K.P.K., Himalaya Pakistan. The total nine road cut slopes and his twenty-seven joint sets were scan lines mapped along the Karakoram highway based on their geological characteristics and instability conditions. Data collect from all these selected sites and give the proper name to every rock slope from ks.1 to ks.9.

The following data collected along the highway are as under:

- Lithological description of rock

- Slope height

- Slope face angle

- Orientation of Joints (dip and dip direction)

- Discontinuity Condition (persistence, aperture roughness, and weathering)

- Block Size

- U.C.S.

The following above mentioned data has been collected in the field, according to ISRM [28]. The three sets of discontinuities present in all these chosen slopes and data obtained from all three discontinuities are set individually in Table 1. Scan line mapping gives us detailed geotechnical information about the area for the incorporation of the methodology. The joint spacing data show four types of rock mass classes present in these slopes: massive, blocky/seamy, fracture, and shattered. The condition of discontinuity of rock mass surface shows that slightly whether to highly whether of rock surface present. The infilling data show that most joints have no filing except some joints filled by soil or weathered material. 


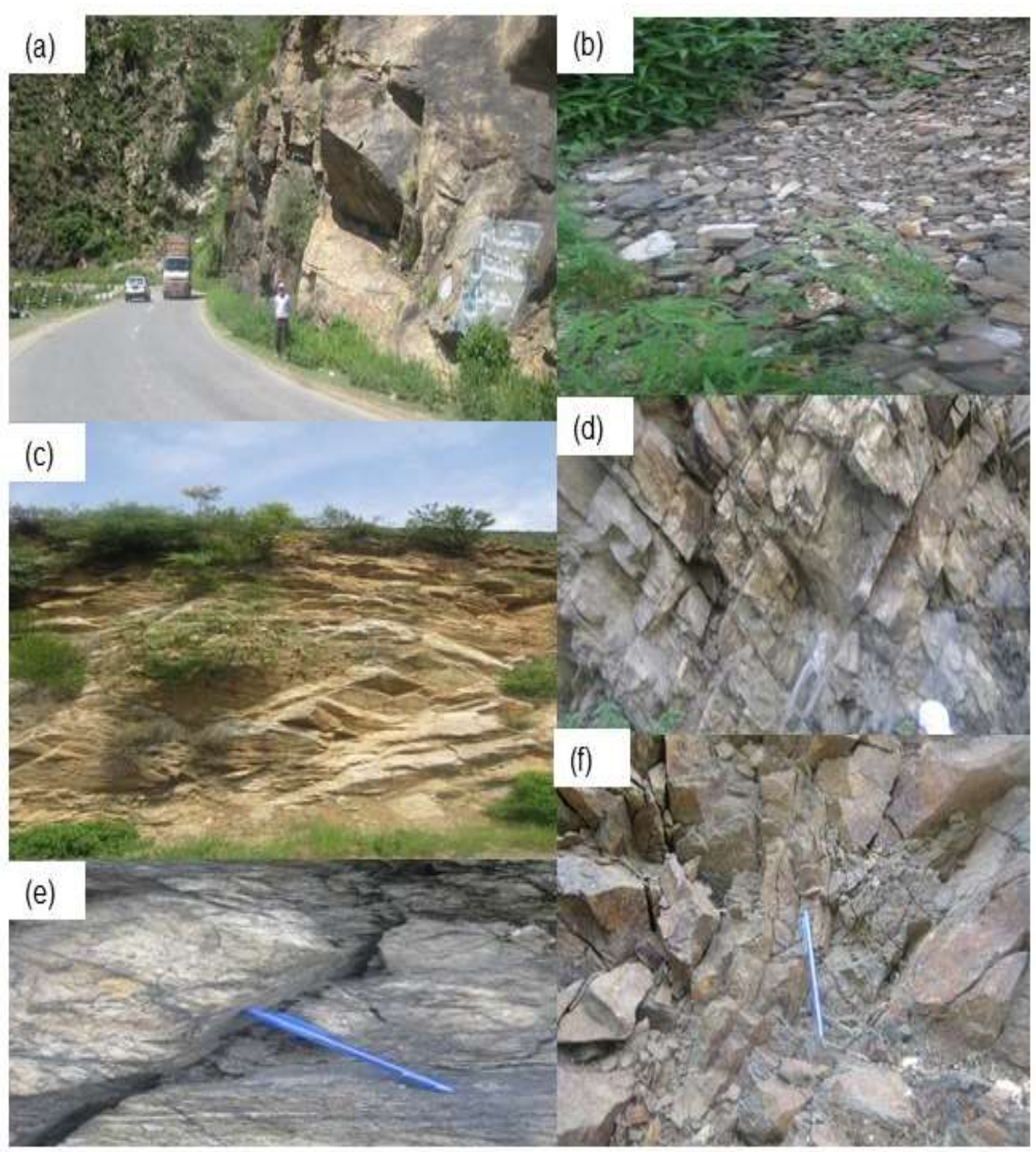

Figure.3 Field figures taken from the field: (a) show the massive to blocky discontinuities (b) show unstable material (c) show the toppling and wedge failure mode (d) show the high weather and fractured discontinuities (e) show the roughness and infilling of discontinuities (d) shows the highly whether and fractured discontinuities. The roughness data show that smooth, slightly rough to very rough discontinuities rock mass present.

The water condition of all these discontinuities shows that all the discontinuities surface was dry. The N-Type Shidmit hammer was used to determining the uniaxial compressional strength (U.C.S.) of the rocks. A total of 20 rebound values of Shidmit hammer was taken from each slope according to the [29] ISRM method. The following expression 4.52927 exp (0.5609RL) by [30] was used for the estimate of uniaxial compressional strength (U.C.S.) of the rock 
mass. The number of discontinuities (joints) volumetric Jv, an indirect method of rock quality designation (R.Q.D.) by [31], was used to obtain rock quality designation. The above-mentioned collected data applied to calculate RMRb, S.M.R., and analysis for kinematic analysis.

Table.1 Detailed field investigation data

\begin{tabular}{|c|c|c|c|c|c|c|c|c|c|c|c|}
\hline $\begin{array}{l}\text { Slope } \\
\text { Name }\end{array}$ & $\begin{array}{l}\text { Slope } \\
\text { height } \\
\text { (m) }\end{array}$ & $\begin{array}{l}\text { Slope face } \\
\text { Dip/Dip } \\
\text { Direction ( }{ }^{0} \text {. }\end{array}$ & $\begin{array}{l}\text { Discontinuity } \\
\text { Sets }\end{array}$ & $\begin{array}{l}\text { Orientation } \\
\text { Dip/Dip } \\
\text { Direction }\left({ }^{\circ}\right) \\
\end{array}$ & $\begin{array}{l}\text { Spacing } \\
(\mathrm{mm} / \mathrm{m})\end{array}$ & $\begin{array}{l}\text { Persistence } \\
\text { (m) }\end{array}$ & $\begin{array}{l}\text { Aperture } \\
(\mathrm{mm})\end{array}$ & Infilling & Roughness & Weathering & $\begin{array}{l}\text { Water } \\
\text { Condition }\end{array}$ \\
\hline \multirow[t]{3}{*}{ Ks. 1} & 12 & $60^{\circ} / 330$ & Ks.1-1 & $78^{\circ} / 219^{0}$ & $0.6-2 \mathrm{~m}$ & $10-20$ & $1-2$ & Soil & Slightly & Slightly & Dry \\
\hline & & & Ks.1-2 & $6^{0} / 030^{\circ}$ & $60-200$ & $<1$ & $0.1-1$ & - & Smooth & - & - \\
\hline & & & Ks.1-3 & $55^{0} / 330^{\circ}$ & $200-600$ & $3-10$ & $0.1-1$ & - & Slightly & - & - \\
\hline \multirow[t]{3}{*}{ Ks. 2} & 13 & $50^{\circ} / 205^{0}$ & Ks.2-1 & $80^{\circ} / 200^{\circ}$ & $200-600$ & $10-20$ & $>5$ & Soil & Smooth & Moderately & Dry \\
\hline & & & Ks.2-2 & $30^{\circ} / 240^{\circ}$ & $60-200$ & $<1$ & $>5$ & - & - & - & - \\
\hline & & & Ks.2-3 & $50^{\circ} / 360^{\circ}$ & $60-200$ & $1-3$ & $1-5$ & - & - & - & - \\
\hline \multirow[t]{3}{*}{ Ks. 3} & 8 & $50^{\circ} / 40^{0}$ & Ks.3-1 & $35^{\circ} / 030^{\circ}$ & $200-600$ & $1-3$ & $0.1-1$ & Soil & Smooth & Moderately & Dry \\
\hline & & & Ks.3-2 & $55^{\circ} / 220^{\circ}$ & - & $1-3$ & $1-5$ & - & Slightly & - & - \\
\hline & & & Ks.3-3 & $65^{\circ} / 150^{\circ}$ & - & $1-3$ & $0.1-1$ & - & Smooth & - & - \\
\hline \multirow[t]{3}{*}{ Ks. 4} & 12 & $40^{\circ} / 145^{0}$ & Ks.4-1 & $40^{\circ} / 350^{\circ}$ & $200-600$ & $10-20$ & $0.1-1$ & Soil & Smooth & Highly & Dry \\
\hline & & & Ks.4-2 & $90^{\circ} / 090^{\circ}$ & $>60$ & $10-20$ & $1-5$ & - & Slightly & Highly & _- \\
\hline & & & Ks.4-3 & $45^{\circ} / 150^{\circ}$ & $>60$ & $1-3$ & $1-5$ & - & Smooth & Highly & _- \\
\hline \multirow[t]{3}{*}{ Ks. 5} & 10 & $65^{0} / 120^{0}$ & Ks.5-1 & $50^{\circ} / 090^{\circ}$ & $200-600$ & $10-20$ & $0.1-1$ & Soil & Slightly & Moderately & Dry \\
\hline & & & Ks.5-2 & $70^{\circ} / 180^{\circ}$ & - & $3-10$ & - & - & - & - & - \\
\hline & & & Ks.5-3 & $45^{0} / 335^{0}$ & - & $10-20$ & - & - & - & - & - \\
\hline \multirow[t]{3}{*}{ Ks. 6} & 8 & $50^{\circ} / 140^{0}$ & Ks.6-1 & $55^{0} / 145^{0}$ & $200-600$ & $3-10$ & $1-5$ & Soil & Slightly & Moderately & Dry \\
\hline & & & Ks.6-2 & $60^{0} / 215^{0}$ & - & $1-3$ & - & - & - & - & - \\
\hline & & & Ks.6-3 & $75^{\circ} / 330^{\circ}$ & $60-200$ & $<6$ & - & - & - & - & - \\
\hline \multirow[t]{3}{*}{ Ks.7 } & 9 & $55^{0} / 320^{0}$ & Ks.7-1 & $30^{\circ} / 315^{0}$ & $60-200$ & $>20$ & $0.1-1$ & Soil & Smooth & Highly & Dry \\
\hline & & & Ks.7-2 & $65^{\circ} / 200^{\circ}$ & - & $>20$ & $1-5$ & - & - & - & - \\
\hline & & & Ks.7-3 & $80^{\circ} / 305^{0}$ & - & $>20$ & $1-5$ & - & - & - & - \\
\hline \multirow[t]{3}{*}{ Ks. 8} & 18 & $70^{\circ} / 230^{0}$ & Ks.8-1 & $45^{\circ} / 200^{\circ}$ & $60-200$ & $1-3$ & $1-5$ & Soil & Slightly & Highly & Dry \\
\hline & & & Ks.8-2 & $55^{\circ} / 300^{\circ}$ & - & $>20$ & 5 & - & Verry & - & - \\
\hline & & & Ks.8-3 & $70^{\circ} / 090^{\circ}$ & - & $3-10$ & $0.1-1$ & - & Slightly & - & - \\
\hline \multirow[t]{3}{*}{ Ks. 9} & 10 & $50^{\circ} / 222^{0}$ & Ks.9-1 & $15^{0} / 325^{0}$ & $200-600$ & $>20$ & $0.1-1$ & Soil & Slightly & Slightly & Dry \\
\hline & & & Ks.9-2 & $75^{\circ} / 030^{\circ}$ & $60-200$ & $1-3$ & $0.1-1$ & - & - & - & - \\
\hline & & & Ks.9-3 & $80^{\circ} / 220^{\circ}$ & $200-600$ & $1-3$ & $0.1-1$ & - & - & - & - \\
\hline
\end{tabular}

\section{Methodology}

The R.M.R. classification was first introduced by [32][9]. After that, this classification is widely used worldwide for assessing rock mass quality. The basic R.M.R. system by [9] comprised of five basic parameters; (1) Uniaxial Compressional Strength of rock, (2) Rock quality Designation (R.Q.D.), (3) Spacing of discontinuities, (4) Condition of discontinuities, (5) Groundwater condition. In this $\mathrm{RMR}_{\mathrm{b}}$ classification system, the spacing of discontinuities further divided into (a) Persistence, (b) Aperture, (c) Roughness, (d) Infilling, and weathering. The sum of these five parameters from 0 to 100 ranges. R.M.R. clarification system was first widely used and adopted worldwide. S.M.R.

The S.M.R. classification system proposed by [11] calculated using four correction factors in RMRb. These four factors are based on the relationship 
among rock mass of discontinuities, slope face dip, dip direction, and excavations method.

$\mathrm{SMR}=\mathrm{RMRb}+\left(\mathrm{F}_{1} \cdot \mathrm{F}_{2} \cdot \mathrm{F}_{3}\right)+\mathrm{F}_{4}$

Where

$F_{1}$ refers to the parallelism between slope face $\operatorname{dip}\left(\alpha_{\mathrm{s}}\right)$ and discontinuity dip direction $\left(\alpha_{\mathrm{j}}\right)$. Its range lies in between 0.15 , very favorable to $1: 0$, very unfavorable (Table 2); in case of planar and toppling failure, $\mathrm{A}$ is the angle between dip direction face and discontinuity dip direction. $F_{2}$ refers to the discontinuity dip angle for planar failure mode. For toppling failure, this parameter takes the range 1.00, and for planar failure, this parameter takes the range between 0.5 to 1.00 (Tables 1). F3 refers to a relationship between $\beta_{\mathrm{s}}$ slop face dip and $\beta_{\mathrm{j}}$ joint dip. For planar and toppling failure, this parameter used the original Bienienwski adjustment factor range between 0 to -60 and referred to the probability of the joint slope face for planar failure. F4 refers to the correction factor, which depends on the excavation method. (Table.2) The values are shown in Table 2 [33] suggests another possible continuous function for calculation $F_{1}$ and $\mathrm{F}_{2}$ :

Table 2. $F_{1}, F_{2}, F_{3}$, and $F_{4}$ (excavation method) Correction factors for joints [33].

\begin{tabular}{|c|c|c|c|c|c|c|c|}
\hline Type of Failure & & & Very favorable & Favorable & Normal & Unfavorable & Very Unfavorable \\
\hline $\mathbf{P}$ & A & $\left|\alpha_{\mathrm{J}} \alpha_{\mathrm{s}}\right|$ & $>30^{\circ}$ & $30-20^{\circ}$ & $20-10^{0}$ & $10-5^{0}$ & $<5^{0}$ \\
\hline$T$ & & $\left|\alpha_{j}-\alpha_{s}-180\right|$ & & & & & \\
\hline w & & $\left|\alpha_{i}-\alpha_{s}\right|$ & & & & & \\
\hline $\mathbf{P} / \mathbf{T} / \mathbf{W}$ & $\mathrm{F}_{1}$ & & 0.15 & 0.40 & 0.70 & 0.80 & 1.00 \\
\hline $\mathbf{P} / \mathbf{W}$ & B & $|\beta \mathrm{j}|$ or $\left|\beta_{\mathrm{i}}\right|$ & $<20^{\circ}$ & $20-30^{\circ}$ & $35-35^{\circ}$ & $35-45^{0}$ & $>45^{0}$ \\
\hline $\mathbf{P} / \mathbf{W}$ & $\mathrm{F}_{2}$ & & 0.15 & 0.40 & 0.70 & $0.85^{0}$ & 1.00 \\
\hline$T$ & & & 1.00 & & & & \\
\hline $\mathbf{P}$ & $\mathrm{C}$ & $\beta_{j}-\beta_{s}$ & $>10^{0}$ & $10-0^{0}$ & $0^{0}$ & $0-\left(-10^{0}\right)$ & $<\left(-10^{0}\right)$ \\
\hline w & & $\beta_{\mathrm{j}} \beta_{\mathrm{s}}$ & & & & & \\
\hline $\mathbf{T}$ & & $\beta_{j+} \beta_{s}$ & $<110^{\circ}$ & $110-120>$ & $>120$ & - & - \\
\hline $\mathbf{P} / \mathbf{T} / \mathbf{W}$ & $\mathrm{F}_{3}$ & & 0 & -6 & -25 & -50 & -60 \\
\hline $\begin{array}{l}\text { Excavation } \\
\text { method }\end{array}$ & $\mathrm{F}_{4}$ & $\begin{array}{l}\text { Natural } \\
\text { Slope }+15\end{array}$ & Presplitting +10 & $\begin{array}{l}\text { Smooth blasting } \\
+8\end{array}$ & $\begin{array}{ll}\begin{array}{l}\text { Blasting } \\
\text { mechanical 0 }\end{array} & \text { or }\end{array}$ & Deficient blasting -8 & \\
\hline
\end{tabular}

Note: P Planar failure mode; T: Toppling failure mode; W: wedge failure mode; $\alpha_{\mathrm{j}}$ : joint slope direction; $\alpha_{\mathrm{s}}$ : slope dip direction; $\beta_{\mathrm{j}}$ : joint dip; $\beta_{\mathrm{s}}$ slope dip

$\mathrm{F}_{1}=(1-\sin |\mathrm{A}|)^{2}$

A is the relation between the joints and the slope dip direction for toppling, planar failure, and wedge failure mode. A is the angle created between the two 
joints intersection, the direction of plunge, and the slope dip direction. This function is credible for all valid values of $\mathrm{A}$ and given a more balanced value for $F_{1}$ than the original discrete function.

$\mathrm{F}_{2}=\tan ^{2} \mathrm{~B}$

$\mathrm{B}$ compares to the joint dip $\left(\mathrm{B}_{\mathrm{j}}\right)$ in degree for toppling and planar failure and $(\mathrm{Bi})$ plunge of the intersection line's wedge failure. Its actual value for the range of $\mathrm{B}$ is lower than $45^{\circ} . \mathrm{F}_{2}$ is set to 1 for a higher value. Therefore, this function does not apply to all $\mathrm{B}$ values, which are discrete functions. It is also unreasonable because it provides a value of $\mathrm{F}_{2}$ that is lower than that suggested in the original function. The asymmetrical continuous correction factors of $F_{1}, F_{2}$, and $F_{3}$ proposed by [17] Table 3, which given most absolute difference compared to the original discrete function, are less than 7 points and no doubt reducing subjective perception when applying the score to values close to the boundaries of discrete classification intervals.

Table 3. Continuous function suggested by[17].

\begin{tabular}{lll}
\hline Parameter & Planar & Toppling \\
\hline $\mathrm{F}_{1}$ & $F_{1}=\frac{16}{25}-\frac{3}{500} \arctan \left(\frac{1}{10}(|A|)-17\right)$ & \\
$\mathrm{F}_{2}$ & $F_{2}=\frac{9}{16}+\frac{1}{195} \arctan \left(\frac{17}{100} B-5\right)$ & $F_{2}=1$ \\
$\mathrm{~F}_{3}$ & $F_{3}=-30+\frac{1}{3} \arctan C$ & $F_{3}=-13-\frac{1}{17} \arctan (C-120)$ \\
& & \\
\hline
\end{tabular}

A correlation between joint and slope strikes for planar and toppling failure modes creates the angle between the two discontinuities. $\mathrm{B}$ is the joint dip, $\mathrm{B}_{\mathrm{j}}$ and $\mathrm{C}$ is the joint and slope dip, for planar failure mode, $\mathrm{C}$ is the equivalent to $\beta_{j-} \beta_{S}$ for toppling failure mode $\beta_{j-} \beta_{s}$ for wedge failure mode $\beta_{j-} \beta_{s}$.

The $\mathrm{F}_{4}$ factor depends on the slope's exaction method, and this system is not essential in the continuous system. 
Table 4. S.M.R description by [11]

\begin{tabular}{llllll}
\hline $\begin{array}{l}\text { Class } \\
\text { No. }\end{array}$ & $\begin{array}{l}\text { S.M.R } \\
\text { value }\end{array}$ & Description & Stability & Failure & Support \\
\hline V & O-20 & Very bad & Completely unstable & Big-Planar or soil-like & Re excavation \\
IV & $21-40$ & Bad & Unstable & Planar or big wedge & Important/corrective \\
III & $41-60$ & Fair & Partially stable & Some joint or many wedges & Systematic \\
II & $61-80$ & Good & Stable & Some blocks & Occasional \\
I & $81-100$ & Very good & Completely stable & None & None \\
\hline
\end{tabular}

\section{Kinematic Analysis.}

Markland's test was conducted based on kinematic analysis using Dip 6.0 software[34]. Kinematic analysis is used based on the internal friction angle of rock and orientation of joint sets to identify a different kind of failure mode in rock slopes, such as planar failure mode, wedge failure mode, and toppling failure mode.

\subsection{Planar Failure mode.}

Based on the Markland test described by [35], the kinemetric assessment shows the probability of planar failure mode occurs in eight location sites out of nine sites. The slope site ks. 1 has a very high potential for planar failure mode $31.25 \%$, and slope ks.9 has shown no potential for planar failure mode. The slope site ks.3, which has already failed, and the probability of planar failure mode shown $21.05 \%$ (Fig. 1 . a and b). The slope ks. 2 shows a $25 \%$ possibility of planar failure mode. The slope site ks. 7 shows $33.33 \%$ of probability for planar failure mode, and this is the highest probability of failure in all slope sites. 


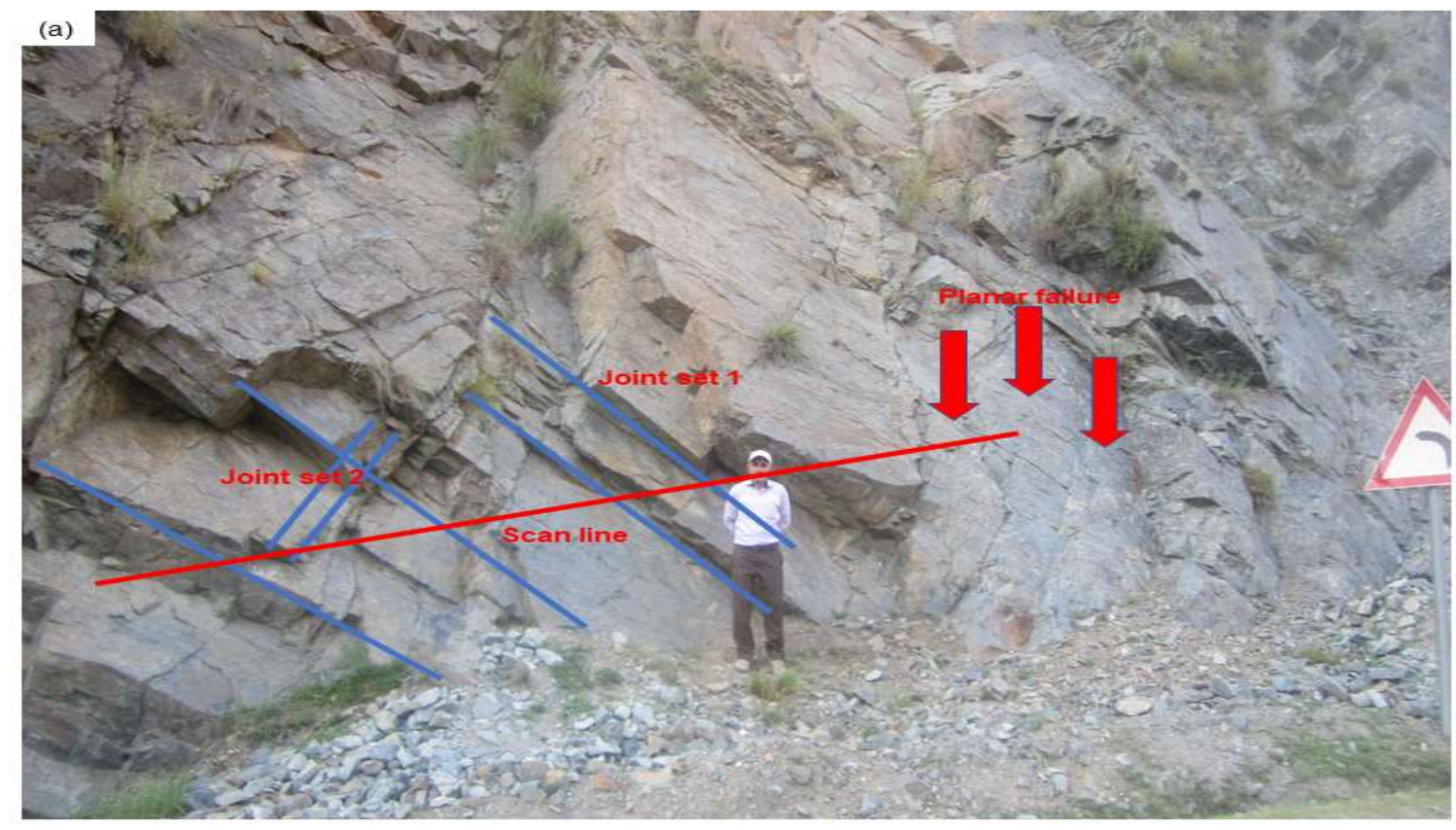

(b)

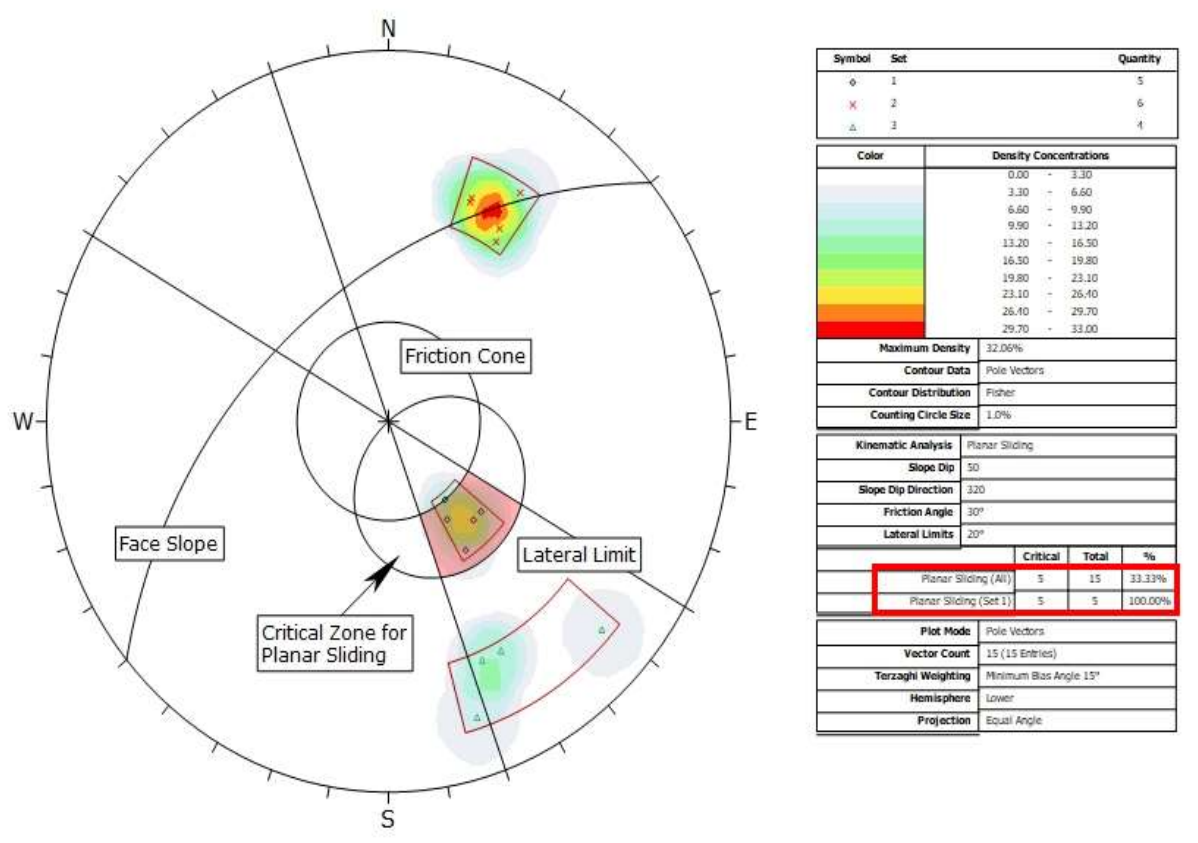

Figure. 4 (a) Slope site Ks.3 shown the scan line, joint sets, and toppling failure mode. (b) the kinematic assessment shows the planar failure mode in slope site Ks.3. 


\subsection{Toppling failure mode.}

The kinematic analysis has shown that both flexural and block toppling failure mode occurs in slope site Ks.1, 6, 7, 8, and 9. The highest $12.50 \%$ flexural toppling mode occurs in slope sit Ks.8, and a minimum of $1.51 \%$ occurs in slope site no.8. The highest $29.41 \%$ block toppling failure mode occurs in slope site Ks.6, and the minimum 26.67 block toppling failure mode occurs in slope site Ks.9.

\subsection{Wedge failure mode.}

The kinematic analysis has shown that the wedge failure mode occurs in all nine slope sites. The highest probability influence of wedge failure mode occurs in slope location ks.5. 66.67\% (Table. 4) and this slope location site were already unstable. The slope location ks. 6 shows a $45.93 \%$ probability of wedge failure mode, the second-largest wedge failure mode probability in all locations.

The location site ks.9 has shown no any possibility of wedge failure mode. The lowest probability is shown in slope site ks.8, just 5.77\% table.no.5

Table 5. Failure mode results based on Kinematic Analysis.

\begin{tabular}{lllll}
\hline $\begin{array}{l}\text { Slope } \\
\text { name }\end{array}$ & Planar failure mode (\%) & Wedge failure mode (\%) & \multicolumn{2}{l}{ Toppling failure mode (\%) } \\
\cline { 4 - 5 } & & & Flexural Toppling Block Toppling \\
\hline Ks.1 & 31.25 & 38.66 & 2.52 & 0.00 \\
Ks. 2 & 25.00 & 0.86 & 0.00 & 0.00 \\
Ks.3 & 21.05 & 21.76 & 0.00 & 0.00 \\
Ks. 4 & 10.53 & 15.32 & 0.00 & 0.00 \\
Ks.5 & 6.67 & 66.67 & 0.00 & 0.00 \\
Ks.6 & 29.41 & 45.93 & 2.22 & 29.41 \\
Ks. 7 & 33.33 & 39.05 & 1.90 & 0.00 \\
Ks. 8 & 6.67 & 5.77 & 12.50 & 0.00 \\
Ks. 9 & 0.00 & 0.00 & 1.51 & 26.67 \\
\hline
\end{tabular}

\section{R.M.R. System.}

All nine chosen road cut slope and discontinuity set assessment shown in (Table.3), the discontinuity set Ks.1-1 to Ks. 1-3 lie score between 66 to 65representing Class "II," a good rock. The discontinuity set Ks.2-1 to Ks.2-3 lies score between 57 to 55, representing class "III" a fair rock. The discontinuity set Ks.3-1 to Ks.3-3 lies in-between scores 62 to 63, representing class "II," a good rock. The location name Ks.3 and its three joint sets lie between 62 and 63, representing class II, a good rock. All slope sites and their discontinuity set a classified from fair to good rock table.no.6. 
Table 6. shows the complete results of the RMRb results.

\begin{tabular}{|c|c|c|c|c|c|c|c|c|}
\hline $\begin{array}{l}\text { Discontinuity } \\
\text { Sets Involved }\end{array}$ & $\begin{array}{l}\text { U.C.S. } \\
\text { (MPa) }\end{array}$ & R.Q.D. \% & $\begin{array}{l}\text { Average } \\
\text { Spacing(mm) }\end{array}$ & $\begin{array}{l}\text { Conditions } \\
\text { discontinuity }\end{array}$ & $\begin{array}{ll}\text { of Water } & \\
& \text { Condition }\end{array}$ & $\begin{array}{l}\text { Total } \\
\text { RMR }_{\mathrm{b}}\end{array}$ & Class & $\begin{array}{l}\text { Discontinuity } \\
\text { Description }\end{array}$ \\
\hline Ks.1-1 & 7 & 17 & 15 & $1+1+3+2+5$ & 15 & 66 & II & Good rock \\
\hline Ks.1-2 & 7 & 17 & 8 & $6+4+1+2+5$ & 15 & 65 & II & Good rock \\
\hline Ks.1-3 & 7 & 17 & 10 & $2+4+3+2+5$ & 15 & 65 & II & Good rock \\
\hline Ks.2-1 & 4 & 17 & 10 & $1+0+0+1+3$ & 15 & 51 & III & Fair rock \\
\hline Ks.2-2 & 4 & 17 & 8 & $6+0+0+3+4$ & 15 & 54 & III & Fair rock \\
\hline Ks.2-3 & 4 & 17 & 8 & $4+1+0+3+4$ & 15 & 53 & III & Fair rock \\
\hline Ks.3-1 & 7 & 17 & 10 & $4+4+1+2+3$ & 15 & 63 & II & Good rock \\
\hline Ks.3-2 & 7 & 17 & 10 & $4+1+3+2+3$ & 15 & 62 & II & Good rock \\
\hline Ks.3-3 & 7 & 17 & 10 & $4+4+1+2+3$ & 15 & 63 & II & Good rock \\
\hline Ks.4-1 & 4 & 17 & 10 & $1+4+1+2+1$ & 15 & 55 & III & Fair rock \\
\hline Ks.4-2 & 4 & 17 & 5 & $1+1+3+2+1$ & 15 & 49 & III & Fair rock \\
\hline Ks.4-3 & 4 & 17 & 5 & $4+4+1+2+1$ & 15 & 53 & III & Fair rock \\
\hline Ks. $5-1$ & 7 & 17 & 10 & $1+4+2+3+3$ & 15 & 59 & III & Fair rock \\
\hline Ks. $5-2$ & 7 & 17 & 10 & $2+4+2+3+3$ & 15 & 60 & III & Fair rock \\
\hline Ks-5-3 & 7 & 17 & 10 & $1+4+2+3+3$ & 15 & 59 & III & Fair rock \\
\hline Ks.6-1 & 12 & 17 & 10 & $2+1+2+3+3$ & 15 & 65 & II & Good rock \\
\hline Ks.6-2 & 12 & 17 & 10 & $4+1+3+2+3$ & 15 & 64 & II & Good rock \\
\hline Ks.6-3 & 12 & 17 & 10 & $6+1+3+2+3$ & 15 & 67 & II & Good rock \\
\hline Ks.7-1 & 12 & 8 & 8 & $0+4+2+1+1$ & 15 & 51 & III & Fair rock \\
\hline Ks.7-2 & 12 & 8 & 8 & $0+1+2+1+1$ & 15 & 48 & III & Fair rock \\
\hline Ks.7-3 & 12 & 8 & 8 & $0+1+2+1+1$ & 15 & 48 & III & Fair rock \\
\hline $\mathrm{Ks}, 8-1$ & 7 & 17 & 8 & $4+1+2+3+1$ & 15 & 57 & II & Good rock \\
\hline Ks. $8-2$ & 7 & 17 & 8 & $0+0+0+6+1$ & 15 & 54 & II & Good rock \\
\hline Ks. $8-3$ & 7 & 17 & 8 & $2+4+2+3+1$ & 15 & 59 & II & Good rock \\
\hline Ks.9-1 & 4 & 17 & 10 & $0+4+2+3+5$ & 15 & 60 & III & Fair rock \\
\hline Ks.9-2 & 4 & 17 & 8 & $4+4+2+3+5$ & 15 & 62 & II & Good rock \\
\hline Ks.9-3 & 4 & 17 & 10 & $4+4+2+3+5$ & 15 & 64 & II & Good rock \\
\hline
\end{tabular}

\section{S.M.R. System.}

An open-source software S.M.R. toll

(http://personal.us.es/en/ariquelme/smartool.html) develop by [21] is used for accurate and automatic calculation. This software tool is suitable for both the engineer and geologist with the graphical representation of the geometry data used as the S.M.R. calculation input and directs them during the entire process. A 12-meter-high structurally control road slope name Ks.1, is composed of slightly weathered gneiss rock and three joint sets present in this slope. All the essential geomechanically data that has been taking during fieldwork summarized in table no.6. The slope name Ks.1 and all three joint sets calculate according to the software author's instructions in the S.M.R. tool software. The joint set ks.1-1, both discrete by [33] and continuous by [17], has S.M.R. values 62 and 61 belong to class "II" its stability condition is stable. The potential failure is toppling. The joint set Ks.1-2 has S.M.R. values 63 and 62 and lies in class "II" and has stable stability conditions except for some blocks, and the 
possible failure mode is wedge/planar. The joint set Ks.1-3 has calculated S.M.R. values 16 and 12, both discrete and continue.

The joint set Ks.1-3 lies in class "V" and has very bad stability condition or completely unstable except for some blocks, and the possible failure mode is big planar or wedge. According to the software description, the element of the wedge also calculates in all three joint sets. Therefore, we choose a proper name for all three joints sets for identification. The joint set Ks.1 Ks.1-3 element of wedge failure calculation shows that S.M.R. values 61 and 61, which lies in class II and has a good and normal description and stability condition show stable and partially stable, and the failure mode is a wedge. The joint set ks. 1 Ks.2-3 element of wedge calculation shows that S.M.R. values are 57 and 51, which belong to Class II. The description shows normal also has partially stable stability conditions, and the failure mode is a wedge.

A 13 meter-high structurally controlled rode cut slope name Ks.2, is composed of slightly weathered gneiss rock with an orthogonal join set present in this slop. The joint discontinuity set Ks.2-1 calculated S.M.R. failure mode. The discontinuity set Ks.2-2, which has calculated S.M.R. values 55 to 44 and belongs to class "III," a normal description that is partially stable in his stability condition. The failure mode is the planar failure mode. The joint set Ks.2-3, which calculated S.M.R. value 53 and 52, and this discontinuity set belongs to the class "III," and partially stabile its stability condition. The failure mode is the toppling failure mode. 
Table 7. Both discrete function by [33] and continuous function by [17]calculated results from SMRTool software.

\begin{tabular}{|c|c|c|c|c|c|c|c|c|c|c|c|c|c|c|c|c|}
\hline \multirow[t]{3}{*}{ Slope Name } & \multirow{3}{*}{$\begin{array}{l}\text { Discontinuity } \\
\text { involved }\end{array}$} & \multirow[t]{3}{*}{ sets } & \multirow[t]{3}{*}{ Type of failure mode } & \multicolumn{3}{|c|}{$\begin{array}{l}\text { Auxiliary } \\
\text { angle } C\end{array}$} & \multicolumn{8}{|c|}{ S.M.R. factor } & \multirow{3}{*}{$\begin{array}{l}\text { S.M.R. value } \\
\text { Discrete } \\
\text { function }\end{array}$} & \multirow{3}{*}{$\begin{array}{l}\text { Continues } \\
\text { function }\end{array}$} \\
\hline & & & & \multirow[t]{2}{*}{ A } & \multirow[t]{2}{*}{ в } & \multirow[t]{2}{*}{ c } & \multicolumn{3}{|c|}{ Discrete ffunction } & & \multicolumn{3}{|c|}{ Continues function } & \multirow[b]{2}{*}{$\mathrm{F} 4$} & & \\
\hline & & & & & & & $\mathrm{F} 1$ & $\mathrm{~F} 2$ & $\mathrm{~F} 3$ & $\mathrm{~F} 4$ & $\overline{\mathrm{F} 1}$ & $\mathrm{~F} 2$ & $\mathrm{~F} 3$ & & & \\
\hline \multirow[t]{5}{*}{ K..1 } & K. $1-1-1$ & & Toppling & 69 & 78 & 131 & 0.15 & 1 & -25 & 0 & 0.16531 & 1 & -254029 & 0 & 62 & 61 \\
\hline & Ks.1-2 & & Planar & 60 & 6 & .54 & 0.15 & 0.15 & -60 & 0 & 0.17855 & 0.17329 & -59.6464 & 0 & 63 & 63 \\
\hline & Ks.1-3 & & Planar & 0 & 55 & -5 & 1 & 1 & -50 & 0 & 0.99721 & 0.95765 & -56.23 & 0 & 15 & \\
\hline & Ks.1 Ks.1-3 & & Wedge & 35.34 & 49.36 & -10.64 & 0.15 & 0.15 & -60 & 0 & 0.27161 & 0.93978 & -58.2103 & 0 & 56 & ${ }_{55}$ \\
\hline & Ks.1 Ks.2-3 & & Wedge & 86.21 & 5.39 & -56.61 & 0.15 & 0.15 & -60 & 0 & 0.14933 & 0.17151 & -59.6503 & 0 & 63 & 63 \\
\hline \multirow[t]{6}{*}{$\mathrm{Ks.2}$} & Ks $2-1$ & & Planar & 5 & 80 & 30 & 0.85 & 1 & 0 & 0 & 0.94117 & 0.99003 & -0.06363 & 0 & 51 & 50 \\
\hline & Ks $2-2$ & & Planar & 30 & 30 & -20 & 0.15 & 0.4 & -60 & 0 & 0.59179 & 1 & -59.0459 & 0 & 50 & 44 \\
\hline & Ks $2-3$ & & Toppling & 25 & 50 & 100 & 0.4 & 1 & 0 & 0 & 0.40804 & 0.29578 & -0.55107 & 0 & 53 & 52 \\
\hline & Ks.2.2 Ks.1-2 & & Wedge & 80.94 & 21.88 & -28.12 & 0.15 & 0.4 & -60 & 0 & 0.15333 & 0.29578 & -29.3218 & 0 & 47 & 48 \\
\hline & Ks.2 Ks.1-3 & & Wedge & 81.57 & 18.77 & -31.23 & 0.15 & 0.15 & -60 & 0 & 0.15282 & 0.24033 & -59.3887 & 0 & 49 & 48 \\
\hline & Ks.2 Ks.2-23 & & Wedge & 83.66 & 20.87 & -29.33 & 0.15 & 0.4 & -60 & 0 & 0.15119 & 0.27816 & -59.3446 & 0 & 49 & 50 \\
\hline \multirow[t]{6}{*}{ K..3 } & Ks $3-1-1$ & & Planar & 20 & 30 & -5 & 0.2 & 0.7 & -50 & 0 & 0.5358 & 0.78574 & -56.21 & 0 & 49 & 39 \\
\hline & Ks $3-2$ & & Toppling & 10 & 55 & 95 & 0.7 & 1 & 0 & 0 & 0.84995 & 1 & -0.47009 & 0 & 62 & 61 \\
\hline & Ks.3-3 & & Toppling & 80 & 65 & 105 & 0.15 & 1 & 0 & 0 & 0.15411 & 1 & -0.68772 & 0 & 63 & 62 \\
\hline & Ks.3 Ks.1-2 & & Wedge & 86.71 & 4.68 & 54.68 & № & & & & & & & & 100 & 100 \\
\hline & Ks.3 Ks.1-3 & & Wedge & 33.66 & 26.86 & -23.11 & 0.4 & 0.4 & -60 & 0 & 0.43802 & 0.44224 & -59.5493 & 0 & 53 & 51 \\
\hline & Ks.3 Ks.2-3 & & Wedge & 19.2 & 53.7 & 103.4 & Non & & & & & & & & 100 & 100 \\
\hline \multirow[t]{6}{*}{ Ks.4 } & Ks.4-1 & & Planar & 5 & 40 & -5 & 0.85 & 0.85 & -50 & 0 & 0.94117 & 0.87504 & -56.23 & 0 & 18 & 8 \\
\hline & Ks.4-2 & & Toppling & 20 & 40 & 85 & 0.4 & 1 & 0 & 0 & 0.5398 & 1 & -0.37165 & 0 & 49 & 48 \\
\hline & Ks.4-3 & & Planar & 60 & 90 & 45 & 0.15 & 1 & 0 & 0 & 0.17855 & 0.9956 & -0.42434 & 0 & 53 & 52 \\
\hline & Ks.4 Ks.1-2 & & Wedge & 82.5 & 10.29 & -34.71 & 0.1 & 0.15 & -60 & 0 & 0.15208 & 0.18865 & -59.4499 & 0 & 47 & 47 \\
\hline & Ks.4 Ks.1-3 & & Wedge & 30 & 34.5 & -10.5 & 0.15 & 0.7 & -60 & 0 & 0.32541 & 0.77204 & -58.1855 & 0 & 46 & 38 \\
\hline & Ks.4 Ks.2-3 & & Wedge & 30 & 39.57 & 84.57 & № & & & & & & & & 100 & 100 \\
\hline K. .5 & Ks.s-1 & & Planar & 30 & 50 & -15 & 0.15 & 1 & -60 & 0 & 0.32541 & 0.94227 & -58.7286 & 0 & 50 & 40 \\
\hline
\end{tabular}




\begin{tabular}{|c|c|c|c|c|c|c|c|c|c|c|c|c|c|c|c|}
\hline & Ks.5-2 & Planar & 60 & 70 & 5 & 0.15 & 1 & -6 & 0 & 0.17855 & 0.98175 & -3.77 & 0 & 59 & 59 \\
\hline & Ks.5-3 & Toppling & 35 & 45 & 110 & 0.15 & 1 & -6 & 0 & 0.27433 & 1 & -0.968666 & 0 & 58 & 58 \\
\hline & Ks.s Ks.1-2 & Wedge & 6.65 & 47.55 & -17.45 & 0.85 & 1 & -60 & 0 & 0.91756 & 0.93189 & .58 .9067 & 0 & 8 & 8 \\
\hline & Ks.5 Ks.1.-3 & Wedge & 89.31 & 30.26 & 95.26 & № & & & & & & & & 100 & 100 \\
\hline & Ks.5 Ks:2-23 & Wedge & 30.36 & 17.52 & 82.52 & № & & & & & & & & 100 & 100 \\
\hline \multirow[t]{7}{*}{ K. .6} & Ks. $6-1$ & Planar & 5 & 55 & 5 & 0.85 & 1 & -6 & 0 & 0.94117 & 0.95765 & -3.77 & 0 & 59 & 61 \\
\hline & K. $6-2$ & Planar & 75 & 60 & 10 & 0.15 & 1 & -6 & 0 & 0.15869 & 0.96822 & -1.9035 & 0 & 63 & 63 \\
\hline & K. $6-3$ & Toppling & 10 & 75 & 125 & 0.7 & 1 & -25 & 0 & 0.84995 & 1 & -24.2414 & 0 & 49 & 46 \\
\hline & Ks.6 Ks.1-2 & Wedge & 32.18 & 51.89 & 1.79 & 0.15 & 1 & -6 & 0 & 0.30025 & 0.94851 & -9.7301 & 0 & 63 & 61 \\
\hline & Ks. $6 \mathrm{Ks.1.-3}$ & Wedge & 81.38 & 5.15 & 44.85 & 0.15 & 0.15 & -60 & 0 & 0.15297 & 0.17285 & -59.5742 & 0 & 63 & 63 \\
\hline & Ks.6 Ks:2-2 & Wedge & 60.63 & 51.07 & 101.0 & № & & & & & & & & 100 & 10 \\
\hline & Ks, $6 \mathrm{Ks} 2.23$ & Wedge & 60.63 & 51.07 & 101.0 & & & & & & & & & 100 & 100 \\
\hline \multirow[t]{6}{*}{ Ks.7 } & K. $7-1$ & Planar & 5 & 30 & -25 & 0.85 & 0.4 & -60 & 0 & 0.94117 & 0.59179 & -59.2365 & 0 & 30 & 18 \\
\hline & Ks. $7-2$ & Toppling & 60 & 65 & 120 & 0.15 & 1 & -25 & 0 & 0.17855 & 1 & -13 & 0 & 44 & 45 \\
\hline & Ks.7-3. & Planar & 15 & 80 & 25 & 0.7 & 1 & 0 & 0 & 0.70786 & 0.99003 & -0.76354 & 0 & 48 & 47 \\
\hline & Ks.7 Ks.1.12 & Wedge & 44.36 & 24.65 & -30.35 & 0.15 & 0.4 & -60 & 0 & 0.22912 & 0.36995 & -59.3709 & 0 & 43 & 44 \\
\hline & Ks:7 Ks.1.-3 & Wedge & 73.83 & 30.36 & -48.64 & 0.15 & 0.15 & -60 & 0 & 0.15984 & 0.17434 & -59.6074 & 0 & 47 & 47 \\
\hline & Ks:7 Ts:2.23 & Wedge & 86. & 60.21 & -5.21 & 0.15 & 0.15 & -60 & 0 & 0.14906 & 0.94962 & -3.2532 & 0 & 63 & 63 \\
\hline \multirow[t]{6}{*}{ К. 8} & К. $8-1$ & Planar & 30 & 45 & -25 & 0.15 & 0.85 & -60 & 0 & 0.32541 & 0.91802 & -59.2365 & 0 & 49 & 39 \\
\hline & Ks. $8-2$ & Planar & 70 & 55 & -15 & 0.15 & 1 & -60 & 0 & 0.16411 & 0.95768 & -58.7286 & 0 & 45 & 4 \\
\hline & K. $8 .-3$ & Toppling & 40 & 70 & 140 & 0.15 & 1 & -25 & 0 & 0.24099 & 1 & -25.4482 & 0 & 55 & 52 \\
\hline & Ks.8 Ks.1-12 & Wedge & 11.58 & 36.8 & -33.2 & 0.7 & 0.85 & -60 & 0 & 0.81075 & 0.82647 & -59.4249 & 0 & 18 & 14 \\
\hline & Ks.8 Ks.1.-3 & Wedge & 66.92 & 38.64 & -31.36 & 0.15 & 0.85 & -60 & 0 & 0.16797 & 0.8573 & -59.3912 & 0 & 49 & 48 \\
\hline & Ks:8 Ks:2-3 & Wedge & 39.84 & 25.86 & 95.86 & 0.15 & 1 & 0 & 0 & 0.24187 & 1 & -0.48173 & 0 & 54 & 53 \\
\hline \multirow[t]{6}{*}{ K.9. } & Ks:9-1 & Toppling & 77 & 15 & 65 & 0.15 & 1 & 0 & 0 & 0.15677 & 1 & -0.29166 & 0 & 60 & 59 \\
\hline & Ks.9-2 & Toppling & 12 & 75 & 125 & 0.7 & 1 & -25 & 0 & 0.79939 & 1 & -24.2414 & 0 & 44 & 42 \\
\hline & Ks.9-3 & Planar & 2 & 80 & 30 & 1 & 1 & 0 & 0 & 0.97786 & 0.99003 & -0.63638 & 0 & 64 & 63 \\
\hline & Ks.9 Ks.1-2 & Wedge & 81.84 & 14.03 & -39.57 & 0.15 & 0.15 & -60 & 0 & 0.1526 & 0.2828 & -59.4692 & 0 & 58 & 58 \\
\hline & Ks.9 Ks.1-3 & Wedge & 85.42 & 24.33 & -35.67 & 0.15 & 0.15 & -60 & 0 & 0.14989 & 0.21023 & -59.4647 & 0 & 58 & 58 \\
\hline & $\mathrm{Ks}, 9 \mathrm{Ks} 2.3$ & Wedge & 84.03 & 21.42 & -28.58 & 0.15 & 0.4 & -60 & 0 & 0.15091 & 0.2874 & -59.332 & 0 & 58 & 59 \\
\hline
\end{tabular}


An eight meter-high structurally controlled slope name Ks.3, is comprised of moderately whether ultramafic pyroxenite rocks with orthogonal joint sets. The joint set Ks.3-1 calculated S.M.R. values 49 to 39, which belong to class "III" normal condition in discrete function and class "IV" partially stable condition in continuous function. The failure mode belongs to toppling failure. The joint set Ks.3-2 calculated S.M.R. values 62 to 61 , which belong to class "II" stable condition in both discrete and continuous function. The failure mode belongs to the toppling mode. The joint set Ks.3-3 calculated S.M.R. values 63 to 62, which belong to class "II" stable condition in both discrete and continuous function. The failure mode belongs to the toppling mode. The joint set Ks.3 Ks.1-2 calculated S.M.R. values has 100. Therefore, this joint is non-feasible. The joint set Ks.3 Ks.1-3 calculated S.M.R. values 53 to 51, which belong to class "III" partially stable condition in discrete and continuous function. The failure mode belongs to wedge failure. The joint set Ks.3 Ks.2-3 calculated S.M.R. value is 100, and this joint is non-feasible.

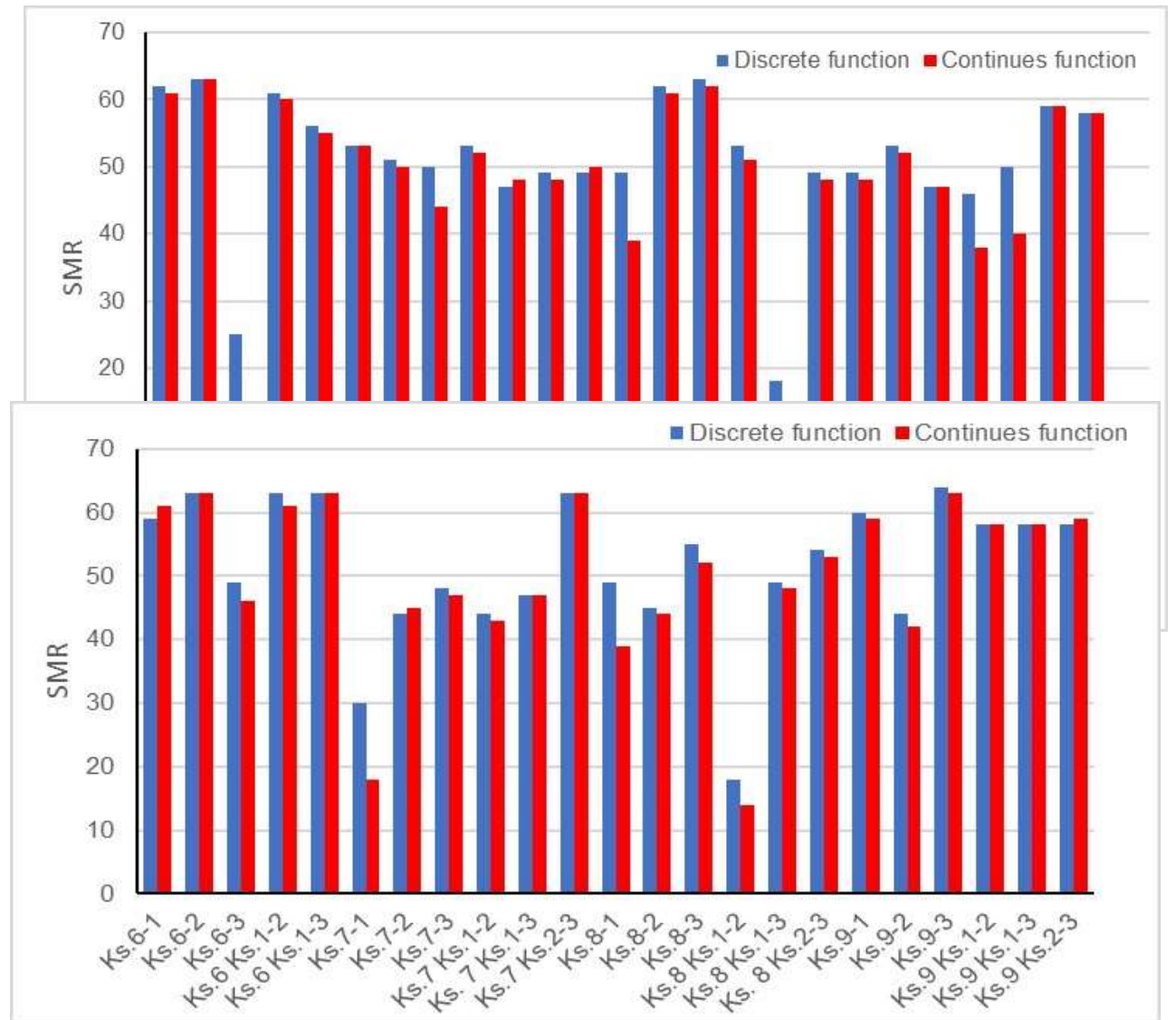

Figure 5. Both discrete function by Roman (1993a) and continuous function by Tomas et al. (2007) calculated results from SMRTool software.

A 12-meter-high slope name Ks.4 comprised of highly weathered gneiss rock with orthogonal joint sets. The joint set Ks.1-1, both discrete and continuous calculated S.M.R. values, is 18 to 8 , which belongs to class "V," completely 
unstable its stability condition and failure mode big planar or soil. The joint set Ks.1-2, both discrete and continues calculated S.M.R. values are 49 to 48 , which belong to class "III" partially stable its stability condition and the failure mode is Toppling failure. The joint set Ks.1-3, both discrete and continues S.M.R. values are 53 to 52, which belong to class "III" partially stable its stability condition and the failure mode is wedge/planar failure. The joint set Ks.4 Ks.1-2 discrete and continues calculated S.M.R. values are 47 to 47 , which belongs to class "III" partially stable its stability condition and failure mode are wedge failure.

The joint set Ks.4 Ks.1-3 both discrete and continuous calculated S.M.R. values are 46 to 38 , which belong to class "II" partially stable and class "IV" unstable its stability condition and the failure mode is wedge failure. The joint set Ks.4 Ks.2-3 both calculated S.M.R. values are 100. Therefore, this joint set is non-feasible Fig. 5 .

A 10-meter high structurally controlled slope name Ks.5 comprises moderately whether gneisses rock with orthogonal joint sets. The joint set Ks.51, both discrete and continuous calculated S.M.R. values are 50 to 40, which belong to class "III" partially stable and class "IV" unstable its stability condition and the failure mode is big planar/wedge failure fig.

The joint set Ks.5-2, both discrete and continuous calculated S.M.R. values are 59 to 59, which belong to the class "III," partially stable its stability condition, and the failure mode is a planar failure. The joint set Ks.5-3, both discrete and continuous calculated S.M.R. values are 58 to 58, which belong to class "III" partially stable its stability condition and the failure mode is Toppling failure. The joint set Ks.5 Ks.1-2 discrete and continues S.M.R. values are 8 to 8, which belongs to class "V" completely unstable its stability condition and failure mode are wedge failure. The joint set Ks.5 Ks.1-3 and Ks.5 Ks., 2-3, both discrete and continues S.M.R. values are 100. Therefore, these two joint sets are non-feasible.

An 8-meter high structurally controlled slope name Ks.6, comprises moderately whether gneisses rock with orthogonal joint sets. The joint set Ks.61 both discrete and continues calculated S.M.R. values are 59 to 61, which belong to class "III" partially stable its stability condition and class "II" stable its stability condition. The failure mode is a planar failure. The joint set Ks.6-2 discrete and continues calculated S.M.R. values are 63 to 63, which belongs to class "II" stable its stability condition, and the failure mode is a planar failure. The joint set Ks.63 , both discrete and continuous calculated S.M.R. values are 49 to 46, which belong to class "III" partially stable its stability condition and the failure mode is toppling failure. The joint set Ks.6 Ks.1-2 discrete and continues S.M.R. values are 63 to 61, which belongs to class "II" stable its stability condition and failure mode are wedge failure. The joint set Ks.6 Ks.1-3 both discrete and continues S.M.R. values are 63 to 63 which belong to class "II" stable its stability condition 
and the failure mode is wedge failure. The joint set Ks.6 Ks.2-3 both discrete and continues S.M.R. values are 100. Therefore, this joint set is non-feasible Fig.5.

Table no.8. Actual field observation compares both (S.M.R) discrete and continuous function assessment.

\begin{tabular}{|c|c|c|c|c|c|c|c|}
\hline \multirow{2}{*}{$\begin{array}{l}\text { Slope } \\
\text { Name }\end{array}$} & \multirow{2}{*}{$\begin{array}{l}\text { Discontinuity set } \\
\text { Involved }\end{array}$} & \multirow{2}{*}{$\begin{array}{l}\text { Actual Field } \\
\text { Observation }\end{array}$} & \multicolumn{2}{|c|}{ S.M.R. Continues function } & \multicolumn{2}{|c|}{ S.M.R. Discrete function } & \multirow[t]{2}{*}{ Failure Mode } \\
\hline & & & Rating & Stability & Rating & Stability & \\
\hline \multirow[t]{3}{*}{ Ks.1 } & Ks.1-1 & Stable & $62(\mathrm{II})$ & Stable & 61(II) & Stable & Toppling \\
\hline & Ks.1-2 & Stable & 63(II) & Stable & 63(II) & Stable & Planar \\
\hline & Ks.1-3 & P. Stable & $16(\mathrm{~V})$ & Unstable & $12(\mathrm{~V})$ & Unstable & Planar \\
\hline \multirow[t]{3}{*}{ Ks. 2} & Ks.2-1 & P. Stable & $51(\mathrm{III})$ & Stable & 59 (III) & Stable & Planar \\
\hline & Ks.2-2 & P. Stable & $55(\mathrm{III})$ & P. Stable & 44(III) & P. Stable & Planar \\
\hline & Ks.2-3 & P. Stable & $53(\mathrm{III})$ & P. Stable & $52(\mathrm{III})$ & P. Stable & Planar \\
\hline \multirow[t]{3}{*}{ Ks. 3} & Ks.3-1 & Unstable & 49(III) & P. Stable & 39(IV) & P. Stable & Planar \\
\hline & Ks. $3-2$ & P. Stable & 62(II) & Stable & 61(II) & Stable & Toppling \\
\hline & Ks.3-3 & P. Stable & 63(II) & Stable & 62(II) & Stable & Toppling \\
\hline \multirow[t]{3}{*}{ Ks. 4} & Ks.4-1 & P. Sable & $18(\mathrm{~V})$ & Unstable & $8(\mathrm{~V})$ & Unstable & Planar \\
\hline & Ks. $4-2$ & P. Stable & 49(III) & Stable & 48(III) & Stable & Toppling \\
\hline & Ks.4-3 & P. Stable & 46(II) & P. Stable & $38(\mathrm{IV})$ & Unstable & Planar \\
\hline \multirow[t]{3}{*}{ Ks. 5} & Ks.5-1 & Unstable & 50 (III) & P. Stable & $40(\mathrm{IV})$ & Unstable & Planar/Wedge \\
\hline & Ks. $5-2$ & Unstable & $52(\mathrm{III})$ & P. Stable & 59 (III) & P. Stable & Toppling \\
\hline & Ks.5-3 & Unstable & $58(\mathrm{III})$ & P. Stable & $58(\mathrm{III})$ & P. Stable & Toppling \\
\hline \multirow[t]{3}{*}{ Ks.6 } & Ks.6-1 & P. Stable & 59(III) & P. Stable & 61(III) & P. Stable & Planar \\
\hline & Ks.6-2 & P. Stable & 63(III) & P. Stable & 63(III) & P. Stable & Planar \\
\hline & Ks.6-3 & P. Stable & 49(III) & P. Stable & 46(III) & P. Stable & Toppling \\
\hline \multirow[t]{3}{*}{ Ks.7 } & Ks.7-1 & Unstable & $30(\mathrm{IV})$ & Unstable & $10(\mathrm{~V})$ & C. Unstable & Planar/Wedge \\
\hline & Ks.7-2 & Unstable & 44(III) & $\mathrm{P} /$ Stable & 45(III) & P. Stable & Planar \\
\hline & Ks.7-3 & Unstable & 48(III) & $\mathrm{P} /$ Stable & 47(III) & P. Stable & Planar \\
\hline \multirow[t]{3}{*}{ Ks. 8} & Ks.8-1 & P. Stable & 49(III) & P. Stable & 39(IV) & P. Stable & Planar/Wedge \\
\hline & Ks.8-2 & P. Stable & $18(\mathrm{IV})$ & C. Unstable & 14(IV) & C. Unstable & Planar/Wedge \\
\hline & Ks.8-3 & Stable & $55(\mathrm{III})$ & P. Stable & $52(\mathrm{III})$ & P. Stable & Toppling \\
\hline \multirow[t]{3}{*}{ Ks.9 } & Ks.9-1 & Stable & 60 (III) & P. Stable & 59 (III) & P. Stable & Toppling \\
\hline & Ks.9-2 & Stable & 44(III) & P. Stable & 42(III) & P. Stable & Planar \\
\hline & Ks.9-3 & Stable & $58(\mathrm{III})$ & P. Stable & $58(\mathrm{III})$ & P. Stable & Planar/Wedge \\
\hline
\end{tabular}

The above Table .8 compares the actual field condition of the selected joint sets with calculated S.M.R values, and the accuracy of the results is more than $90 \%$, which is very satisfactory.

A 9-meter road cut slope name Ks.7 comprised of highly whether gneisses rock with orthogonal joint sets. The joint set Ks.7-1 both discrete and continues S.M.R. values are 30 to 10 which belong to class "IV" unstable its stability condition and class "V" completely unstable its stability condition and the failure mode is a wedge or planar failure. The calculated to 10 which belong to class "IV" unstable its stability condition and class "V" completely unstable its stability condition and the failure mode is a wedge or planar failure. The calculated S.M.R. 
result of this discontinuity set very similar to field observation because this joint set is completely unstable fig. below.

The joint set Ks.7-2 discrete and continues S.M.R. values are 44 to 45, which belongs to class "III" partially stable its stability condition and the failure mode is Toppling failure. The joint set Ks.7-3, both discrete and continues S.M.R. values are 48 to 47 , which belong to class "III" partially stable its stability condition and the failure mode is Planar failure. The joint set Ks.7 Ks.1-2 discrete and continues S.M.R. values are 44 to 43 , which belongs to class "III" partially stable its stability condition and the failure mode is wedge failure. The joint set Ks.7 Ks.1-3 both discrete and continues calculated S.M.R. values are 46 to 46 which belong to class "III" partially stable its stability condition and the failure mode is wedge failure.

The joint set Ks.7 Ks.2-3 both discrete and continues calculated S.M.R. values are 47 to 47 which belong to class "III" partially stable its stability condition and the failure mode is wedge failure.

An 18-meter high structurally controlled road cut slope name Ks.8 comprises highly weathered gneisses rock with orthogonal joint sets. The joint set Ks.8-1 both discrete and continues calculated S.M.R. values are 49 to 39 which belong to class "III" partially stable its stability condition and class "IV" unstable its stability condition and the failure mode is a planar failure.

The joint set Ks.8-2 discrete and continues calculated S.M.R. values are 45 to 44 , which belongs to class "III" partially stable its stability condition and failure mode are a planar failure. The joint set Ks.8-3, both discrete and continuous calculated S.M.R. values, is 55 to 52, which belongs to class "III" partially stable its stability condition, and the failure mode is toppling failure. The joint set Ks.8 Ks.1-2 discrete and continuous calculated S.M.R. values are 18 to 14, which belongs to class "V" completely unstable its stability condition and failure mode are wedge failure. The joint set Ks. 8 Ks.1-3 both discrete and continues calculated S.M.R. values are 49 to 48 which belong to class "III" partially stable its stability condition and the failure mode is wedge failure.

The joint set Ks. 8 ks.2-3, both discrete and continuous calculated S.M.R. value is 100 . Therefore, this joint set is non-feasible.

A 10-meter structurally controlled road cut slope name Ks.9 comprises of slightly whether quartzite rock with orthogonal joint sets. The joint set Ks.9-1, both discrete and continuous calculated S.M.R. values are 60 to 59 which belong to class "III" partially stable its stability condition and the failure mode is Toppling failure. The joint set Ks.9-2 discrete and continues calculated S.M.R. values are 44 to 42 , which belongs to class "III" partially stable its stability condition and failure is toppling failure. 
The joint set Ks.9-3, both discrete and continuous calculated S.M.R. values are 64 to 63 , which belong to class "II" stable its stability condition, and the failure mode is a planar failure. The joint set Ks.9 Ks.1-2 discrete and continues calculated S.M.R. values are 58 to 58 , which belongs to class "III" partially stable its stability condition and failure mode are wedge failure. The joint set Ks.9 Ks.13 both discrete and continues calculated S.M.R. values are 58 to 58 which belong to class "III" partially stable its stability condition and the failure mode is planar/wedge failure. The joint set Ks.9 Ks.2-3 both discrete and continues calculated S.M.R. values are 58 to 59 which belong to class "III" partially stable its stability condition and the failure mode is wedge failure

\section{Discussion}

This paper focused on the Rock Mass Classification system for rock slope stability assessment of highly jointed road cut slopes in northern Pakistan. Two Rock Mass Classification systems, such as (1) Rock Mass Rating (R.M.R.), (2) Slope Mass Rating (S.M.R.), both discrete and continuous, function applied in this study. Slope Mass Rating system (S.M.R.) is widely used worldwide for a preliminary study of rock stability in civil and mining engineering. The key benefit of using a rock mass classification system is that it is an easy and straightforward way to interpret rock mass value and summarize precedent practice[36]. Some limitation in rock mass classifications system, noted by [16] that rock mass classifications system considered variable related with the intact rock strength, geometry of slope, Spacing of discontinuity, block size and shear strength along discontinuities, including some of them are difficult or even impossible to calculate such as water pressure or have a minimal effect on slope stability. The chosen study area is significant due to the highly active landslide zone identified in previous research [20].

The kinematic assessment of the rock slope showed that all kinds of failure modes such as planar, toppling, and wedge failure occur in the study area. However, in this study, we identified that the study area is highly susceptible to rock slope failure along the Karakorum highway due to its rock mass characteristics, adverse discontinuity set, highly whether rock mass and due to soil filling discontinuities. The calculated R.Q.D. data showed that values range from $78 \%$ to $90 \%$, good quality rock accepts only one value which range is $25 \%$, a poor-quality rock. The kinematic results show that all kinds of failure modes occur in these joints set, but the planar and wedge failure mode failure dominant in all the road-cut rock slopes. The (R.M.R.) system results showed that the chosen road cut slope occurred between a fair and good rock. However, the other trigging factors also involve rock slope stability assessments in the study area, such as rainfall and seismicity, but these trigging mechanisms are absent in the S.M.R system. Both (S.M.R.) discrete and continuous results show that all discontinuities set lie between partially stable, stable unstable, similar to our field 
observation. This study shows that (S.M.R.) continues function given fewer values, and with cross-check with field observation, these fewer values results are more reliable than discrete functions. In S.M.R, results also show the planar and wedge failure mode is dominant in all selected discontinuities.

Conclusion.

This study has shown that due to adverse discontinuity sets, week, and whether rock surface and fair to poor rock quality, the study area is highly susceptible to rock slope failure. We highly recommended immediate slope support such as nets, spot bolting, systematic shotcrete, anchoring, and retaining wall along the Karakorum highway in the study area. The present study assessment gave some valuable information regarding rock slope stability in the study area and more research needs, especially regarding other factors such as rainfall and seismicity. These two factors were also involved in rock slope failures in the study area. The continuous (S.M.R.) system is highly recommended in the Himalayan rock slope assessment because its result is similar to actual field observation.

\section{Lis of abbreviations}

G.S.P. Geological Survey of Pakistan

K.K.H. Karakorum highway

S.M.R. Slope mass rating

R.M.R. Rock mass rating

MMT Main mantle thrust

IKNZ Indus Kohistan seismic zone

Conflict of Interest: The authors strongly confirm that there is no conflict of interest regarding our manuscript.

Author Contribution: Conceptualization, Asif Razzak, methodology, Asif Razzak., supervision, Humming Tang, fieldwork, Ijaz Ahmed., software, Asif Razzak, review and suggestions, Lei Kaung, the authors, whose contributions in this manuscript had been already read and agreed for publication of this article.

Funding: This research was funded by the National Key R\&D Program of China (No.2017YFC1501305), the National Key Scientific Instrument and Equipment Development Project of China (No. 41827808).

Acknowledgment: We highly appreciated Professor. Tang Humming for his financial, technical, and moral support for this study. 
References

[1] Pantelidis L. Rock slope stability assessment through rock mass classification systems. International Journal of Rock Mechanics and Mining Sciences 2008;46:315-25. https://doi.org/10.1016/j.ijrmms.2008.06.003.

[2] Mah DCW\& CW. Rock Slope Engineering. vol. 53. 4th ed. C.R.C; 2004.

[3] Cheng YM, Lansivaara T, Wei WB. Two-dimensional slope stability analysis by limit equilibrium and strength reduction methods. Computers and Geotechnics 2007;34:137-50. https://doi.org/10.1016/j.compgeo.2006.10.011.

[4] Brideau MA, Sturzenegger M, Stead D, Jaboyedoff M, Lawrence M, Roberts N, et al. Stability analysis of the 2007 Chehalis lake landslide based on long-range terrestrial photogrammetry and airborne LiDAR data. Landslides 2012;9:75-91. https://doi.org/10.1007/s10346-011-0286-4.

[5] Lisle RJ, Leyshon PR. Stereographic Projection Techniques for Geologists and Civil Engineers. 2004. https://doi.org/10.1017/cbo9781139171366.

[6] Hoek E. Practical Rock Engineering. 2007.

[7] Deere DU. Technical description of rock cores. Geol. u. Bauw J 1963;28.

[8] Barton N, Lien R, Lunde J. Engineering classification of rock masses for the design of tunnel support. Rock Mechanics 1974;6:189-236.

[9] Bieniawski ZT. ENGINEERING CLASSIFICATION OF JOINTED n.d.

[10] Bieniawski ZT. Engineering Rock Mass Classifications. New York: Wiley; 1989.

[11] Romana M. New adjustment ratings for application of Bieniawski classification to slopes. Proceedings of the international symposium on role of rock mechanics, Zacatecas, Mexico, 1985, p. 49-53.

[12] Chen Z. Recent developments in slope stability analysis. In: Proceedings of the 8th International Congress ISRM, Tokyo, 1995 1995;000.

[13] Hoek E, Kaiser PK, Bawden WF. Support of underground excavation in hard rock: Rotterdam. AA Balkema 1995.

[14] Laubscher DH. Geomechanics classification of jointed rock massesmining applications. Trans Instn Min Metall 1977;86:A1-8.

[15] Unal E. Modified rock mass classification: M-RMR system. Milestones in Rock Engineering 1996.

[16] Hack R. AN EVALUATION OF SLOPE STABILITY 
CLASSIFICATION. In: Proceedings of the EUROCK 2002, Madeira, Portugal, 2002 2002:3-32.

[17] Tomás R, Delgado J, Serón JB. Modification of slope mass rating (SMR) by continuous functions. International Journal of Rock Mechanics and Mining Sciences 2007;44:1062-9. https://doi.org/10.1016/j.ijrmms.2007.02.004.

[18] Romana M, Tomás R, Serón JB. Slope Mass Rating (SMR) geomechanics classification: Thirty years review. 13th ISRM International Congress of Rock Mechanics 2015;2015-MAY:1-10.

[19] Average monthly temperature and rainfall of Pakistan for 1991-2016 at location, $(72.87,34.93)$. World Bank n.d. http://www.climateknowledgeportal.worldbank.org/country/pakistan/clim ate-data-historical.

[20] Ali S, Biermanns P, Haider R, Reicherter K. Landslide susceptibility mapping by using a geographic information system (GIS) along the China-Pakistan Economic Corridor (Karakoram Highway), Pakistan. Natural Hazards and Earth System Sciences 2019;19:999-1022. https://doi.org/10.5194/nhess-19-999-2019.

[21] Pastor JL, Riquelme AJ, Tomás R, Cano M. Clarification of the slope mass rating parameters assisted by SMRTool, an open-source software. Bulletin of Engineering Geology and the Environment 2019;78:6131-42. https://doi.org/10.1007/s10064-019-01528-9.

[22] Kazmi AH, Abbasi IA. STRATIGRAPHY \& HISTORICAL · GEOLOGY OF PAKISTAN. 1979.

[23] Tahirkheli, R. A. K., \& Jan MQ. A prelimi- nary geological map of Kohistan and the adjoining areas, N. Pakistan. Geo Bull Univ Peshawar, I IPakistan 1979.

[24] Shams FA. Petrochemistry of some Granitic Rocks from the Nanga Parbat Massif, NW Himalaya, Pakistan. Geol BullNational Centre of Excelence in Geology, University of Peshawar, Pakistan 11:181-187 1979.

[25] Azam M, Qasim AKM, Yeats RS, Hussain A, Khan SA. New data on the Indus Kohistan seismic zone and its extension into the Hazara - Kashmir Syntaxis , NW Himalayas of Pakistan 2009:339-61. https://doi.org/10.1007/s10950-008-9117-z.

[26] Khan KSA, Latif M, Fayaz A, Khan NA, Khan MSZ. Geological roadlog along the Karakoram highway from Islamabad to Khunjrab pass,Geological Survey of Pakistan. 2000. 
[27] Stead D, Wolter A. A critical review of rock slope failure mechanisms: The importance of structural geology. Journal of Structural Geology 2015;74:1-23. https://doi.org/10.1016/j.jsg.2015.02.002.

[28] Suggested methods for the quantitative description of discontinuities in rock masses. International Journal of Rock Mechanics and Mining Sciences \& Geomechanics Abstracts 1979;16:22. https://doi.org/10.1016/0148-9062(79)91476-1.

[29] Aydin A. ISRM Suggested method for determination of the Schmidt hammer rebound hardness: Revised version. International Journal of Rock Mechanics and Mining Sciences 2009;46:627-34. https://doi.org/10.1016/j.jjrmms.2008.01.020.

[30] Wang H, Lin H, Cao P. Correlation of UCS Rating with Schmidt Hammer Surface Hardness for Rock Correlation of UCS Rating with Schmidt Hammer Surface Hardness for Rock Mass Classification. Rock Mechanics and Rock Engineering 2016. https://doi.org/10.1007/s00603-016-1044-7.

[31] Palmstrom A. Measurements of and correlations between block size and rock quality designation (RQD). Tunnelling and Underground Space Technology 2005;20:362-77. https://doi.org/10.1016/j.tust.2005.01.005.

[32] Bieniawski ZT. The geomechanics classification in rock engineering applications 1979:p.41.48.

[33] Romana MR. A geomechanical classification for slopes: slope mass rating. 1993. https://doi.org/10.1016/b978-0-08-042066-0.50029-x.

[34] Rockscience Inc, Dips 6.0 - graphical \& statical analysis of orientation data. Toronto, Canada. 2012.

[35] Hoek E, Bray JD. Rock slope engineering. CRC Press; 1981.

[36] Hudson JA, Harrison JP. Engineering rock mechanics: an introduction to the principles. Elsevier; 2000. 